\title{
IMPORTED MALARIA TO MAKKAH DISTRICT, SAUDI ARABIA: IS THERE ANY RISK OF LOCAL TRANSMISSION?
}

\author{
By \\ MOHAMED EL-MALKY ${ }^{1.2}$, MOHAMMAD S. ALDOSARI ${ }^{3}$, AHMED ELSENDIONY $^{4,5}$, \\ SAEED A. AL-HARTHI ${ }^{1}$, DINA ZAGHLOUL ${ }^{4,6}$ AND NIVEEN SALAH ${ }^{7}$.
}

Department of Medical Parasitology ${ }^{1,2}$, Faculty of Medicine, Umm Al-Qura University $^{1}$, and Mansoura University ${ }^{2}$, Pathology Division ${ }^{3}$, Department of Laboratory and Blood Bank, King Abdulaziz Hospital ${ }^{3}$, Department of Laboratory and Blood Bank, AlNoor Specialist Hospital ${ }^{4}$, Department of Clinical Pathology ${ }^{5}$, Faculty of Medicine, Cairo University, Department of Medical Parasitology ${ }^{6}$, Faculty of Medicine, Assuit University, Egypt ${ }^{2,5,6}$ and Department of Hematology and Immunology ${ }^{7}$, Faculty of Medicine, Umm Al-Qura University, Makkah, Saudi Arabia ${ }^{1,3,4,7}$

( ${ }^{*}$ Correspondence E. Mail: mmelmalky@uqu.edu.sa)

\begin{abstract}
In Makkah, Saudi Arabia, there is an impending risk of imported malaria. This risk comes from the fact that millions of people, in majority from tropical and subtropical countries where malaria is endemic, visit the country to perform Hajj and Umrah every year. Moreover, millions of expatriates from endemic countries come to Makkah for work. Likewise, many Saudi citizens travel to endemic areas overseas for business and pleasure. We performed a retrospective analysis of all reported malaria cases in Makkah region, Saudi Arabia for years 2014 and 2015. In addition, sorting of mosquito populations in Makkah region was undertaken. Based on national data regarding reported malaria cases, 235 malaria cases were recorded in years 2014 and 2015. Of the reported cases 232 were non-Saudi and only 3 cases were Saudi. Those recorded Saudi cases were just returning from a travel to an endemic area. Most of the cases (79.6\%) were $P$. falciprum and the remaining was $P$. vivax. Infected male represent $62 \%$ and female represent $38 \%$. Age of the majority of reported cases $(71.5 \%)$ lie between 31 and 50 years. Most of reported cases were from Chad, Pakistan, Nigeria and Sudan. Sorting of mosquito populations revealed the absence of malaria vectors in Makkah District.
\end{abstract}

Keywords: Saudi Arabia, Makkah, Imported malaria, Malaria vector.

\section{Introduction}

Malaria is one of the 3 top most communicable diseases of public health concern in the world (Gilles et al, 1993). Malaria is caused by Plasmodium parasites. There are 5 human Plasmodium species that cause malaria, and two of these species, $P$. falciparum and $P$. vivax pose the greatest threat (WHO, 2016a). It is endemic in tropical region of Africa, and part of Asia and Americas. Taking into account the population growth between years 2000 and 2015, the reported cases of malaria decreased globally by $37 \%$ and the number of malaria deaths has decreased by $60 \%$. So, a considerable progress was attained regarding the goal reduction of malaria burden by $75 \%$ by 2015 (WHO, 2016b).

The travelers are among the populations at high risk to contract malaria. National malaria control programs need to take special actions to protect travelers from acquiring malaria infection (WHO, 2016a).

Malaria is mainly transmitted through the bites of female Anopheles mosquitoes, called "malaria vectors". Around $30 \mathrm{spec}-$ ies of Anopheles are vectors of malaria (Massey et al, 2016). The intensity of transmission depends on factors related to the parasite, the vector, the human host, and the environment (CDC, 2016). In places where the mosquito prefers to bite humans rather than animals and when its lifespan is longer, transmission will be more intense. These features characterize the African vector species and constitute the main reason why nearly $90 \%$ of the world's malaria cases are recorded in Africa. Malaria could also be acquired by exposure to infected blood products, congeni- 
tal transmission or laboratory exposure (Feachem et al, 2010).

Vector control is the mainstay to reduce and prevent malaria transmission. If a vector control intervention is optimized within a specific area, the protection will be conferred across the community (Roberts, 2002).

Effective surveillance is mandatory at all check points on the way to eradicate malaria from a given country. Surveillance necessitates collecting all data about the disease and responses as well, then taking action according to the received data. Currently many countries with a high burden of malaria have weak surveillance systems and are not in a situation to evaluate disease distribution and trends, making it difficult to optimize responses and respond to outbreaks. Currently the available tools, and organized efforts between partners, will enable endemic countries to reduce the disease burden and achieve malaria eradication (Hommel, 2008).

Imported malaria infections must be addressed to achieve malaria elimination (Cotter et al, 2013). Most countries define imported malaria as any malaria infection whose origin can be traced to a malarious area outside the country in which the infection was identified (Sturrock et al, 2015).

In Makkah District, there is a continuous risk to import malaria, an estimate of 6 millions of people, in majority from tropical and subtropical countries where malaria is prevalent, visit Makkah for Hajj and Umrah every year. Furthermore, millions of the expatriates from endemic countries come for work. Likewise, many Saudis travel to malaria endemic areas overseas for business and pleasure. These factors certainly increase the incidence of the disease and complicate any attempts for its local control (Al-Farsi et al, 2012). In Makkah, such imported cases represent a serious threat by spreading the parasite among non-immune pilgrims and citizens, if malaria vectors exist in Makkah. Thus, the necessity of an urgent improvement in the mechanisms deployed for malaria control in the country. In 1963, Saudi Arabia signed a pre-eradication program plan with the WHO and started the eradication of vectors of infection, large-scale vector control, public health education, and training of health workers on the control and management of malaria (Coleman et al, 2013).

To investigate the possibility of local malaria transmission in Makkah, Saudi Arabia, a retrospective analysis of all reported malaria cases in Makkah District was done, for years $2014 \&$ 2015. Also, sorting of mosquito populations was undertaken.

\section{Materials and Methods}

Data collection: All confirmed malaria infections reported to the Centre of Malaria Elimination program in Makkah, Saudi Arabia during years 2014 and 2015 were collected. The policy of all health centers is to subject clinically suspected malaria cases to thin and thick blood films. All confirmed malaria cases in hospitals, centers and primary health care centers should be reported to the local malaria elimination program unit with 24 hours of diagnosis. Then all collected data are faxed to the headquarters of the malaria elimination program unit. Data is analyzed and sent weekly to the preventive medicine section within the ministry of health.

Mosquito adult and larvae were collected from all water sources by dipping and netting (El-Bashier et al, 2006) for taxonomic characters by standard identification keys (Lane and Crosskey, 1993; Morsy et al, 1995; Abdoodn and Al Shahrani, 2003).

\section{Results}

Confirmed malaria cases were 116 in 2014 and 119 in 2015. Out of the cases 232 were non-Saudis and 3 cases were Saudis. Those Saudis were just returning from a travel to an endemic area. Most of the cases $(76 \%)$ were $P$. falciprum and the rest (14\%) were $P$. vivax. Infected male represent $62 \%$ and female represent $38 \%$. Age of the majority of reported cases $(71.5 \%)$ 
lie between 31 and 50 years. Cases were from Chad, Pakistan, Nigeria and Sudan
(Tabs. 1, 2 \& 3). Examination of mosquitoes showed no malaria vectors.

Table 1: Data of reported malaria cases in Makkah Year 2014

\begin{tabular}{|l|c|c|c|c|c|c|c|c|c|}
\hline \multirow{2}{*}{ Country } & \multicolumn{2}{|c|}{ Plasmodium } & \multicolumn{2}{|c|}{ Sex } & $1-10$ & $11-30$ & $31-50$ & $>50$ & Total \\
\cline { 2 - 9 } & falciparum & vivax & $\mathrm{M}$ & $\mathrm{F}$ & $\mathrm{Y}$ & $\mathrm{Y}$ & $\mathrm{Y}$ & $\mathrm{Y}$ & \\
\hline Chad & 25 & 5 & 24 & 6 & 0 & 3 & 23 & 4 & 30 \\
\hline Pakistan & 9 & 15 & 11 & 13 & 0 & 2 & 8 & 14 & 24 \\
\hline Sudan & 19 & 0 & 12 & 7 & 2 & 3 & 12 & 2 & 19 \\
\hline Nigeria & 10 & 3 & 6 & 7 & 0 & 1 & 10 & 2 & 13 \\
\hline India & 8 & 0 & 5 & 3 & 0 & 0 & 8 & 0 & 8 \\
\hline Mali & 7 & 0 & 5 & 2 & 0 & 0 & 7 & 0 & 7 \\
\hline Yemen & 6 & 0 & 5 & 1 & 0 & 1 & 4 & 1 & 6 \\
\hline Burkina Faso & 2 & 0 & 1 & 1 & 0 & 0 & 2 & 0 & 2 \\
\hline Ethiopia & 2 & 0 & 0 & 2 & 0 & 1 & 1 & 0 & 2 \\
\hline Bangladesh & 1 & 0 & 1 & 0 & 0 & 0 & 1 & 0 & 1 \\
\hline Kenya & 1 & 0 & 1 & 0 & 0 & 1 & 0 & 0 & 1 \\
\hline Cameron & 1 & 0 & 1 & 0 & 0 & 0 & 1 & 0 & 1 \\
\hline Gambia & 1 & 0 & 1 & 0 & 0 & 0 & 1 & 0 & 1 \\
\hline Somali & 1 & 0 & 1 & 0 & 0 & 0 & 0 & 1 & 1 \\
\hline Total & $\mathbf{9 3}$ & $\mathbf{2 3}$ & $\mathbf{7 4}$ & $\mathbf{4 2}$ & $\mathbf{2}$ & $\mathbf{1 2}$ & $\mathbf{7 8}$ & $\mathbf{2 4}$ & $\mathbf{1 1 6}$ \\
\hline
\end{tabular}

Table 2: Malaria cases in Makkah Year 2015

\begin{tabular}{|c|c|c|c|c|c|c|c|c|c|}
\hline \multirow[t]{2}{*}{ Country } & \multicolumn{2}{|c|}{ Plasmodium } & \multicolumn{2}{|c|}{ Sex } & \multirow{2}{*}{$\begin{array}{c}1-10 \\
Y\end{array}$} & \multirow{2}{*}{$\begin{array}{c}11-30 \\
Y\end{array}$} & \multirow{2}{*}{$\begin{array}{c}31-50 \\
Y\end{array}$} & \multirow{2}{*}{$\begin{array}{c}>50 \\
Y\end{array}$} & \multirow[t]{2}{*}{ Total } \\
\hline & falciparum & vivax & $\mathrm{M}$ & $\mathrm{F}$ & & & & & \\
\hline Chad & 17 & 3 & 10 & 10 & 1 & 2 & 16 & 1 & 20 \\
\hline Pakistan & 7 & 14 & 14 & 7 & 0 & 0 & 9 & 12 & 21 \\
\hline Sudan & 12 & 0 & 5 & 7 & 1 & 0 & 11 & 0 & 12 \\
\hline Nigeria & 24 & 4 & 20 & 8 & 0 & 1 & 22 & 5 & 28 \\
\hline India & 3 & 0 & 2 & 1 & 0 & 0 & 2 & 1 & 3 \\
\hline Mali & 5 & 0 & 3 & 2 & 0 & 0 & 5 & 0 & 5 \\
\hline Yemen & 3 & 0 & 3 & 0 & 0 & 0 & 3 & 0 & 3 \\
\hline Burkina Faso & 4 & 0 & 3 & 1 & 0 & 0 & 3 & 1 & 4 \\
\hline Ethiopia & 6 & 0 & 2 & 4 & 0 & 0 & 5 & 1 & 6 \\
\hline Bangladesh & 0 & 0 & 0 & 0 & 0 & 0 & 0 & 0 & 0 \\
\hline Kenya & 0 & 0 & 0 & 0 & 0 & 0 & 0 & 0 & 0 \\
\hline Cameron & 5 & 1 & 1 & 5 & 1 & 0 & 5 & 0 & 6 \\
\hline Gambia & 0 & 0 & 0 & 0 & 0 & 0 & 0 & 0 & 0 \\
\hline Somali & 2 & 0 & 1 & 1 & 0 & 0 & 1 & 1 & 2 \\
\hline Afghanistan & 1 & 3 & 4 & 0 & 0 & 0 & 3 & 1 & 4 \\
\hline Mauritania & 2 & 0 & 1 & 1 & 0 & 0 & 2 & 0 & 2 \\
\hline S. Arabia & 3 & 0 & 3 & 0 & 0 & 0 & 3 & 0 & 3 \\
\hline Total & 94 & 25 & 72 & 47 & 3 & 3 & 90 & 23 & 119 \\
\hline
\end{tabular}

Table 3: Malaria cases in Makkah (both years 2014 and 2015)

\begin{tabular}{|c|c|c|c|c|c|c|c|c|}
\hline P. falciparum & P. vivax & Male & Female & $1-10 \mathrm{Y}$ & $11-30 \mathrm{Y}$ & $31-50 \mathrm{Y}$ & $>50 \mathrm{Y}$ & Total \\
\hline 187 & 48 & 146 & 89 & 5 & 15 & 168 & 47 & 235 \\
$79.6 \%$ & $20.4 \%$ & $62 \%$ & $38 \%$ & $2.1 \%$ & $6.4 \%$ & $71.5 \%$ & $\% 20$ & $100 \%$ \\
\hline
\end{tabular}

\section{Discussion}

Malaria is a preventable and curable disease; increased efforts considerably reduced the malaria burden in many places. To cata$\log$ the residual and emerging challenges, WHO developed the Global technical strategy for the malaria 2016-2030, which was adopted by the World Health Assembly
(2015). The strategy sets the most determined targets for reductions of malaria. The strategy has three main building blocks. Pillar 1 was to ensure universal access to malaria prevention, diagnosis and treatment. Pillar 2 was to accelerate efforts towards elimination of malaria and achievement of malaria-free status. Pillar 3 was to transform 
malaria surveillance into a core intervention (WHO, 2016c).

Imported malaria is defined as any malaria infection whose origin can be traced to a malarious area outside the country in which the infection was identified (Sturrock et al, 2015).To reduce the input of imported malaria on local transmission, countries should improve diagnostic and therapeutic measures along borders with endemic regions. This can be executed by building health facilities along migration routes and at border crossings, an approach implemented in Saudi Arabia (Coleman et al, 2013).

In the current study, most of the reported malaria cases $(n=232)$, were reported from foreigners coming Makkah to perform Hajj, Umrah or immigrant workers. Only 3 cases were Saudis. For infected Saudis, establishing whether the infection was acquired outside Makkah required knowing the individual's recent travel history, which was verified in these 3 cases. In a similar study carried out in Saudi Arabia from 2008-2011 (Memish et al, 2014), the total number of reported malaria cases were $63,48,93 \& 114$ respectively. Number of reported cases year 2011 $(n=114)$ was close to that of the present study (116 at year $2014 \& 119$ at year 2015). This apparent chronological increase in the reported cases can be explained by better reporting policy accomplished by well trained staff of the Ministry of Health. Moreover, another hypothesis can explain such increase based up on the expansion performed on the holy places to accommodate more pilgrims with the subsequent real increase in their number. The highest prevalence of reported cases was from countries with high incidence of malaria according to WHO (2015) malaria was reported in Pakistan and Sudan (Eastern Mediterranean region), Chad and Nigeria in Africa. In accordance with WHO statistics of Plasmodium species, $P$. falciparum constituted $79.6 \%$ of the reported cases and the rest were $P$. vivax. Reported male cases were nearly double the female cases, a finding which could be explained by higher number of male pilgrims and workers.

The current strategy of Saudi Ministry of Health is moving toward the elimination of vector borne diseases from the kingdom. A considerable progress has been achieved in many aspects (Coleman et al, 2013). The morphological sorted mosquito populations in Makkah region (ongoing project) and verified the absence of anopheles mosquitoes the vectors for malaria.

From the fact that no malaria cases were reported among Saudis without travel history to endemic areas and absence of anopheles mosquitoes in Makkah region, we can conclude that local transmission of malaria in Makkah is unlikely to occur.

Four countries have been certified as malaria eliminated area (WHO, 2016b). These were United Arab Emirates (2007), Turkmenistan (2010), Morocco (2010), and Armenia (2011).

The Saudi Arabia Kingdom has implemented strategies for the eradication of malaria. However, influx of people from countries endemic for malaria for either employment or Hajj makes the country highly susceptible to malaria importation. The Makkah District is known to host millions of immigrants yearly and has a surveillance system to monitor the incidence of malaria (Snow et al, 2013).

\section{Conclusion}

The outcome data showed no risk of local malaria transmission in Makkah as indicated by absence of malaria among Saudi residents without history of travelling abroad together with absence of malaria vectors. Saudi Arabia is looking forward for to be certified as malaria eliminated country.

Nevertheless, regular inspection for the larvae in water sources is a must. One should keep in mind that the Holly Cities in Saudi Arabia are visited nearly all the year around.

Consequently, so many of these visitors come from malaria endemic foci, meanwhile the absence of vectors stoped transmission. 
Conflict of interest: All authors have declared no conflict of interest

\section{References}

Abdoodn, AMMO, Al Shahrani, AM, 2003: Prevalence and distribution of anopheline mosquitoes in malaria endemic areas of Asir region, Saudi Arabia. Eastern Medit. Hlth. J., 9, 3:240-7. Al-Farsi, HM, Al-Hashami, ZS, Bin Dajem, S M, Al-Sheikh, AA, Al-Qahtani, A, et al, 2012: Source of drug resistant Plasmodium falciparum in a potential malaria elimination site in Saudi Arabia. Infect. Genet. Evol. 12, 6:1253-9.

CDC, 2016: Malaria-About Malaria-BiologyMosquitoes-Anopheles. Available at: http://www .cdc.gov/malaria/about/biology/mosquitoes

Coleman, M, Al-Zahrani, M, Coleman, M, Hemingway, J, Omar, A, et al, 2014: A country on the verge of malaria elimination: The Kingdom of Saudi Arabia. PLoS One 9, 9: p.e105980.

Cotter, C, Sturrock, HJ, Hsiang, MS, Liu, J, Phillips, AA, et al, 2013: The changing epidemiology of malaria elimination: new strategies for new challenges. Lancet 382:900-11

EI-Bashier, ZM, Hassan, MI, Mangoud, AM, Etewa, S, Morsy, TA, et al, 2006: A preliminary pilot survey (Culex pipiens) Sharkia Governorate, Egypt. J. Egypt. Soc. Parasitol. 36, 1: 81-92.

Feachem, RG, Phillips, AA, Hwang, J, Cotter, C, Wielgosz, B, 2010: Shrinking malaria map: progress and prospects. Lancet 376, 9752:156678.

Gilles, H, Warrell, D, Bruce-Chwatt, L, 1993: Bruce-Chwatt's: Essential Malariology. London: E. Arnold.
Hommel, M, 2008: Towards a research agenda for global malaria elimination. Malar. J. 7, 1:S18.

Lane, RP, Crosskey, RW, 1993: Mosquitoes (Culicidae). In: Medical Insects and Arachnids. $1^{\text {st }}$ edition; Chapman and Hall, London.

Massey, NC, Garrod, G, Wiebe, A, Henry, A J, Huang, Z, et al, 2016: A global bionomic database for the dominant vectors of human malaria. Sci Data. Mar 1;3:160014. doi: 10.1038/ data. Memish, ZA, Alzahrani, M, Alhakeem, RF, Bamgboye, EA, Smadi, HN, 2014: Toward malaria eradication in Saudi Arabia: evidence from 4-year surveillance in Makkah. Ann. Saudi Med. 34, 2:153-8

Morsy, TA, EI Kadry, AA, Salama, MMI, Sabry, AA, EI Sharkawy, IMA, 1995: Studies on Anopheline larvae in El Faiyum Governorate, Egypt. J. Egypt. Soc. Parasitol. 25, 2:329-54.

Snow, RW, Amratia, P, Zamani, G, Mundia, CW, Noor. AM, 2013: The malaria transition on the Arabian Peninsula: progress toward a malaria-free region between 1960-2010. Adv. Parasitol. 82:205-51.

Sturrock, H, Roberts, K, Wegbreit, J, Ohrt, C, Gosling, R, 2015: Tackling imported malaria: An elimination endgame. Amer. J. Trop. Med. Hyg. 93, 1:139-44.

WHO, 2016a: Malaria. Available at: http://www.who.int/mediacentre/factsheets/fs094/en/. WHO, 2016b: World Malaria Report 2015. Geneva, Switzerland.

WHO, 2016c: Global Technical Strategy for Malaria (2016-2030). http://www.who.int/malaria/areas/global_technical_strategy/draftstrategy/ 